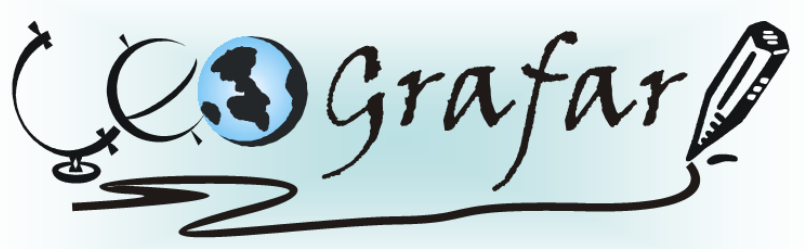

Revista Eletrônica do Programa de Pós-Graduação em Geografia - UFPR

\title{
ABORDAGEM FENOMENOLÓGICA TRANSCENDENTAL E EXISTENCIAL NA GEOGRAFIA: AS BASES PARA O ENTENDIMENTO DO ESPAÇO VIVIDO
}

\author{
ADRIANO BRUNATTO DE ALMEIDA ${ }^{1}$
}

\begin{abstract}
RESUMO
Para a Geografia humanista as abordagens mais significativas são aquelas que evocam a significação espacial e as relações humanas com o espaço vivido. Mas de que maneira podemos compreender essas relações se elas estão carregadas de simbolismos, valores, metas, propósitos ou sentimentos? O aporte teóricometodológico fenomenológico, buscado dentro da filosofia transcendental influenciado por Kant pode contribuir para Geografia humanista-cultural no sentido de propiciar uma vertente científica à percepção. Através da fenomenologia existencialista pode-se interpretar os sentidos humanos, a variabilidade de intenções e os aspectos cognitivos da espacialidade, além de desvendar esse mundo vivido da experiência humana e com isso reconhecer as essências da estrutura perceptiva.
\end{abstract}

Palavras-chave: espaço vivido, fenomenologia, existencialismo.

\section{PHENOMENOLOGICAL APPROACH TRANSCENDENTAL AND EXISTENTIAL IN GEOGRAPHY: THE BASIS FOR UNDERSTANDING THE LIVED SPACE}

\begin{abstract}
For the humanist geography approaches most significant are those that evoke the spatial significance and the human relationships with the lived space. But how can we understand these relationships if they are loaded with symbolism, values, goals, intentions or feelings? The theoretical and methodological phenomenological sought

\footnotetext{
1 Mestrando em Geografia pelo Departamento de Pós-Graduação da Universidade Federal do Paraná. E-mail: brunatto27@pop.com
} 
in philosophy influenced by Kant transcendental can contribute to humanistic and cultural geography in order to give a scientific component to perception. Through the phenomenological existentialist can interpret the human senses, the diversity of intentions and cognitive aspects of spatiality, the uncovering of this lived world of human experience and recognize that the essence of perceptual structure.

Key words: lived space, phenomenology, existentialism.

\section{INTRODUÇÃO}

Esse ensaio pretende defender a abordagem fenomenológica existencialista no entendimento do ser humano e de suas relações espaciais. Essa linha de pensamento abriu novas possibilidades para o pensamento geográfico acerca da compreensão da sociedade atual, no sentido de encontrar respostas para a construção de valores e atitudes e para confrontar novos desafios que se impõem diariamente

Entendemos que as ciências tradicionais, como bem mencionou MerleauPonty (1999), manipula os dados, fabrica modelos teóricos, operando índices, variáveis e transformações, mas que por si só, estão longe de uma realidade do mundo, que possa ser palpável e inteligível pelas pessoas comuns. (MERLEAUPONTY, 1969, p. 25)

Se buscarmos ainda compreender os fenômenos humanos, principalmente aqueles relacionados com as sensações individuais, muitas vezes ficamos órfãos das ciências e suas explicações quantitativas e teoréticas. Assim, logo de início percebe-se a complexidade envolvida nesse entendimento, mesmo porque, não é possível extrair uma realidade universal dos fatos, devido à subjetividade da vida humana e as diferentes formas de sensações envolvidas nos experimentos. De tal maneira que é impossível obter, através de experimentos cartesianos clássicos, explicações das relações humanas. Dessa forma, entendemos que a ciência tradicional dificilmente nos traz respostas satisfatórias aos comportamentos e sentimentos do homem com seu espaço.

Para analisarmos as relações mais sutis ao comportamento do homem com seu espaço, devemos recorrer a uma ciência que procure responder as questões 
mais subjetivas possíveis. Essa ciência é a fenomenologia. Na acepção sobre a fenomenologia, pontuou Tuan:

Ou medimos e mapeamos o espaço e o lugar, e adquirimos leis espaciais e inventários de recursos através de nossos esforços. Estas são abordagens importantes, porém precisam ser completadas por dados experienciais que possamos coletar e interpretar com fidedignidade, porque nós mesmos somos humanos. Temos 0 privilégio de acesso a estados de espírito, pensamentos e sentimentos. Temos a visão do interior dos fatos humanos, uma asserção que não podemos fazer a respeito de outros tipos de fatos. (TUAN, 1983, p. 5)

A humanidade está confrontada com inúmeras questões que não possuem nenhuma resposta satisfatória pela ciência clássica. As pessoas não se vêem representadas em nada de novo explicado pelas teorias e modelos produzidos nos laboratórios. Cada ser humano é um mundo. Todo homem, tem uma maneira particular de pensar e processar as informações que o cercam. Portanto a maneira de representar o seu mundo diferencia-se do seu vizinho. O ser humano não apenas observa e percebe os fenômenos do espaço, mas também cria uma rede complexa de significados para esses fenômenos. (SPOSITO, 2004, p. 74)

Assim, para acessar tal complexidade de análise, se faz necessário analisar filosoficamente as relações do homem com seu espaço vivenciado. O nível de análise da fenomenologia é altamente abstrato, pois ele pode estar associado com "fenômenos observáveis, da realidade, como também de idéias, conceitos, teorias, etc...", e resultante da atividade observacional, sem querer encontrar regras absolutas ou definitivas.

A fenomenologia coloca o homem novamente no mundo, em um solo sensível, repleto de existência e significância humana. E cabe também aos estudiosos da Geografia explorar esta "terra incognitae" da percepção e da mentalidade. Não somente esse solo cheio de erosão de minerais frios e invisíveis, ou esse lugar transcrito em um mapa, mas um lugar habitado. Habitar, não no sentido de apenas morar, mas de cultivar o espaço, viver no ritmo natural, ver a vida na história humana e no símbolo do lugar. 


\section{MÉTODO}

Para o presente estudo o aporte metodológico utilizado foi o levantamento bibliográfico de filósofos que utilizam a filosofia existencialista em suas análises, sobretudo em Kant e Merleau-Ponty. O método fenomenológico em questão não é totalmente desprovido de ambigüidades, mas inscreve as perspectivas filosóficas no debate que opõe os adeptos do idealismo e os defensores do empirismo.

Desde o século $\mathrm{XX}$, o método fenomenológico foi tomado como um pensamento radicalmente novo para os padrões da época. Essa ciência se apresentava como o estudo descritivo de todos os fenômenos que se oferecem a experiência dos sujeitos. (DEPRAZ, 2008, p. 7)

A fenomenologia, dentro do campo de pesquisa de sua área, tem exercido acentuadamente, uma influência considerável no pensamento filosófico e científico contemporâneo, mesmo porque diversos filósofos se inspiraram nas intuições, inicialmente formuladas por Edmund Husserl e, em seus projetos teceram com suas reflexões próprias, novos caminhos e compreensões para a Fenomenologia. Temos em Martin Heidegger, Merleau-Ponty e Jean-Paul Sartre, alguns dos filósofos que se permitiram afetar por este movimento, o qual se situa no seio de uma tradição filosófica cujo eixo central é a dimensão contemplativa do homem. (GONÇALVES, 2008, p. 403)

Anteriormente, o pensamento científico clássico, ou seja, os estudos das ciências da natureza eram fortemente impregnados pela influência dos modelos galileicos e newtonianos da Física. Mas, não tardou que, tais influências também incidissem sobre os domínios das várias ciências, inclusive da Geografia e da Filosofia.

Ao primar os fatos observáveis, e por isso mensuráveis, a Geografia passava também a estar em perfeita sintonia com o positivismo, assim como todas as ciências da época. Com a Filosofia não foi diferente, e os argumentos positivistas direcionavam a busca de uma teoria do conhecimento. A teoria kantiana ganha uma nova roupagem com o movimento denominado neo-kantianismo, direcionada desta feita, para a busca de uma ciência da consciência, que pesquisasse a estrutura do conhecimento. Essa valorização do estudo da consciência, tanto pela psicologia 
quanto pela filosofia, faz com que a psicologia científica, neste caso positivista, seja elevada a ciência básica da filosofia e de todos os outros campos de conhecimento. Nasce assim o "psicologismo" que será um dos principais conceitos criticados futuramente por Husserl. (GONÇALVES, 2008, p. 403)

A obra de Husserl criou toda uma revolução nas perspectivas de produção do conhecimento na civilização ocidental. O filósofo partiu de uma crítica a metafísica, e positivismo, constituindo uma abordagem epistemológica e ontológica fundamentadas não em pressupostos teóricos, mas na própria vivência de consciência pré-reflexiva do sujeito cognoscente, em sua correlação intrínseca com o mundo. Elegeu assim, a vivência de consciência pré-reflexiva do sujeito cognoscente como o critério de produção do conhecimento. (DEPRAZ, 2008, p. 2021)

A fenomenologia não se preocupa em ser exata, mas antes se ocupa dos fenômenos vividos da consciência a partir de um conceito que é fundamental nesta tentativa de relançar a temática da percepção - a consciência intencional. Assim, a Fenomenologia é compreendida como uma filosofia que concebe o entendimento da consciência e sua intencionalidade. O princípio da intencionalidade é que a consciência é sempre "consciência de alguma coisa", e sua análise é análise de todos os modos possíveis como uma coisa pode ser um dado para consciência. (ABBAGNANO, 2001, p. 7)

Assim, todos os tipos de sentidos que se fazem presentes a consciência daquilo que está no espaço e no lugar habitado, que é percebido, sentido, pensado, recordado, simbolizado, amado, desejado, etc., fazem parte da análise fenomenológica. Essa análise só se efetua, em primeiro lugar, se a própria consciência não for assumida como uma "realidade", ao mesmo título das outras realidades do mundo, mas sim como princípio dela, já que a realidade é apenas um dos modos como o fenômeno pode ser dado à consciência. Em segundo, se a consciência assume em relação ao mundo a atitude de um expectador desinteressado, aos quais os fenômenos se apresentam, ou seja, nos modos específicos como eles são dados. (id, 2001, p. 7)

A fenomenologia então, afirma a importância dos fenômenos da consciência os quais devem ser estudados em si mesmos - tudo que podemos saber do mundo 
e do espaço que vivemos e habitamos, resume-se a esses fenômenos, que existem na mente, designados por sua representação do real, por sua essência, sua significação.

Dessa forma, a fenomenologia apresenta-se como fértil contribuição às pesquisas sobre o homem, sua consciência, e suas relações com o espaço e o lugar. Muitos profissionais e pesquisadores da Geografia, sobretudo no âmbito da abordagem humanista-cultural, têm, com efeito, buscado na Fenomenologia um suporte, uma inspiração, subsídios metodológicos ou, até mesmo, um parceiro de diálogo, visando à auto-reflexão crítica, responsável pela maior compreensão da realidade.

\section{DISCUSSÕES}

Para a Fenomenologia, ao contrário do que ocorre com as ciências naturais, fenômenos são também coisas que existem no pensamento, puramente ideais, assim como também aquelas criadas pela ação e pela prática humanas, por exemplo: valores morais, crenças, artes, técnicas, instituições. (BERTOL, 2003, p. 70)

Daí porque Merleau-Ponty (1999, p. 2) define a Fenomenologia como uma "filosofia que repõe as essências na existência". O autor destaca que, por ser definida como uma filosofia transcendental, a fenomenologia coloca o mundo vivido a priori das reflexões e justifica por isso o esforço em compreender o homem e o seu mundo a partir da "facticidade".

Com efeito, podemos encontrar em Immanuel Kant (1724-1804) os princípios de uma filosofia transcendental e que por certo teria sua rede de influências para a filosofia existencialista. Kant discutiu a fundo as (in)certezas metafísicas e postulou a impossibilidade de conclusões e a fraqueza dos argumentos que os cientistas usavam. Kant inspirou-se no ceticismo de David Hume (1711-1776), principalmente em suas críticas à causalidade, que tornavam incertas as posições do racionalismo dogmático.

Em seu livro Crítica da Razão Pura, Kant desfere duras reflexões em relação 
ao universo da ciência racionalista positiva e metafísica:

...quão poucos motivos temos para confiar em nossa razão quando não só nos abandona num dos aspectos mais importantes de nossa ânsia de saber, mas ainda nos entretém com simulações e por fim nos ludibria. (KANT, 2005, Prefácio, p. 38)

Nessa obra, Kant procura distinguir o conhecimento puro do conhecimento empírico destacando que "todo" conhecimento começa com a experiência e com o contato com os objetos que "tocam nossos sentidos e em parte produzem por si representações". Assim Kant define que o conhecimento começa com a experiência, mas também declara que "nem por isso todo ele" se origina dela. O autor destaca que:

...poderia bem acontecer que mesmo nosso conhecimento de experiência seja um composto daquilo que percebemos por impressões e daquilo que nossa própria faculdade de conhecimento (apenas provocadas por impressões sensíveis) fornece de si mesma. (id, pag. 53)

Nesse sentido, Kant define um método "reflexivo". Principalmente porque requer pensar sobre os conhecimentos racionais que possuímos. Kant procura discutir a natureza da própria razão. Portanto o livro Crítica da Razão Pura leva a uma reflexão sobre a maneira como produzimos o conhecimento. Kant define nessa obra dois tipos de conhecimentos explicitados na tabela 01.

O modo explicativo "objetivo" foi muito característico das ciências racionais como a metafísica, e Kant se contrapunha a elas declarando que a substituição da necessidade subjetiva pela necessidade objetiva "que só existem nos juízos à priori" seria o mesmo que negar à razão o poder de conhecer o objeto e ainda rejeitar as causas, como se fosse uma ilusão. (KANT, 2006, prefácio pag. 24) 
TABELA 01 - DIFERENCIAÇÃO DO CONHECIMENTO SEGUNDO KANT

\begin{tabular}{|r|c|}
\hline Conhecimento a priori & Conhecimento a posteriori \\
\hline Conhecimento independente da & Conhecimento obtido e modelado \\
experiência e das impressões dos sentidos. & pela experiência empírica. \\
É o conhecimento puro. Ocorrem \\
independentes das experiências.
\end{tabular}

FONTE: KANT (2005 p. 54); Org.: O autor (2011).

O modo explicativo "objetivo" foi característico das ciências racionais como a metafísica, e Kant se contrapunha a elas declarando que a substituição da necessidade subjetiva pela necessidade objetiva "que só existem nos juízos à priori" seria o mesmo que negar à razão o poder de conhecer o objeto e ainda rejeitar as causas, como se fosse uma ilusão. (KANT, 2006, prefácio pag. 24)

Kant propõe o idealismo transcendental na tentativa de colocar o espírito como elemento ativo na elaboração do conhecimento e a realidade percebida por nós como resultado de uma construção. Segundo o autor:

Muito mais significativo que todo o precedente é o fato de que certos conhecimentos abandonam mesmo o campo de todas as experiências possíveis e parece estender o âmbito de nossos juízos acima de todos os limites da experiência mediante conceitos os quais em parte alguma podem ser dado um objeto correspondente na experiência. (KANT, 2005, p. 56)

Desta feita, Kant propõe uma recusa às argumentações doutrinárias e aos sistemas autocoerentes. Ele fez perceber que as coisas só podem ser apreendidas pela experiência sensível. As formas são conhecidas a priori pelo espírito, enquanto faculdade de conhecimento. Na fala de Merleau-Ponty, Descartes e sobretudo Kant:

Desligaram o sujeito e a consciência, fazendo ver que eu não poderia apreender nenhuma coisa como existente se primeiramente eu não me experimentasse no ato de apreendê-la; eles fizeram aparecer à consciência, a absoluta certeza de mim para mim, como a condição sem a qual não haveria absolutamente nada... (MERLEAU-PONTY, 1999, prefácio, p. 4)

Nesse sentido, as formas a priori, segundo Kant são "os quadros universais" 
pelos quais o espírito conhece o mundo: pela sensibilidade, pela intuição ou pela espontaneidade. Para Kant a sensibilidade é uma capacidade de "obter representações", ou seja, através das intuições sensíveis o objeto é pensado e entendido, originando os conceitos. (KANT, 2005, p. 71)

Kant, portanto, fornece um fio condutor para pensar o lugar e o espaço vivido e experienciado, na medida em que entendemos que podemos analisar o espaço e formular conceitos a partir das intuições sensíveis de algo. A intuição humana supõe um objeto dado e que este nos afeta o espírito. Segundo ele é "pela sensibilidade nos são dados objetos e apenas ela nos fornece intuições". Sobre o conceito de espaço Kant afirma que:

O espaço é uma representação a priori necessária que subjaz a todas as instituições externas. Jamais é possível fazer-se uma representação de que não haja espaço algum, embora se possa pensar que não se encontre objeto algum nele. Ele é, portanto, considerado a condição da possibilidade dos fenômenos e não uma determinação dependente destes. (KANT, 2005, p. 73-74)

Com efeito, pode-se perceber que o espaço está a priori do entendimento e que sua representação é a própria condição da possibilidade dos fenômenos. Nesse caso as relações espaciais são constitutivas do objeto. Nesse sentido, Kant afirma que certos conhecimentos estão além das experiências possíveis e estendem nossos juízos acima de todos os limites da experiência.

Com isso Kant inova e destaca uma estética transcendental que coloca nossa intuição como a própria representação do fenômeno. Segundo ele as nossas intuições só nos permitem atingir os fenômenos e não as coisas em si. (PASCAL, 2009, p. 58). Assim Kant faz uma observação sobre a estética transcendental:

...as coisas que intuímos não são em si mesmas tais quais as intuímos nem que suas relações são em si mesmas constituídas do modo como nos aparecem e que, se suprimíssemos o nosso sujeito ou também apenas a constituição objetiva dos sentidos em geral, em tal caso desapareceriam toda a constituição, todas as relações dos objetos no espaço e no tempo e mesmo espaço e tempo. (KANT, 2005, p. 83)

$\mathrm{Na}$ acepção kantiana as coisas que percebemos, portanto não são em si mesmas, assim como nós as percebemos, pois, o fenômeno é a coisa, tal como esta 
aparece aos espíritos humanos. Lembrando que Kant, fala nas condições subjetivas da estrutura do espírito e não dos aparelhos sensoriais. Portanto, a nossa intuição do objeto depende mais de uma constituição geral da sensibilidade, que é a mesma em todos os homens: "Todas essas coisas enquanto fenômenos não podem existir em si mesmas, mas somente em nós". (id, 2005, p. 83)

Kant, dessa forma, não se fixa no problema do ser em si, mas do conhecimento do ser. Para ele há algumas categorias que resultam da experiência sensitiva, já que todas as experiências humanas se dão na esfera dos sentidos. Mas, dessa forma, do mundo percebo só as aparências, nunca as essências, ou as coisas em si. Como nas sombras de Platão, a mente encontra dificuldade de apreender diretamente, o real como é em si mesmo.

As polêmicas posições de Kant e as discussões sobre a validade do próprio conhecimento são retomados por vários críticos e encontram em Edmundo Husserl (1859-1938) um indispensável contribuidor para as formulações daquilo que seria conhecido como fenomenologia.

Apesar de Husserl, ter uma tendência materialista de mundo, pois define o conhecimento como a "atividade de um sujeito dirigida a um objeto e dando sentido a ele", não poderíamos deixar de citar as contribuições de seus pensamentos, essenciais para a ciência geográfica, mas principalmente para a compreensão e percepção do espaço. Seguindo o fio condutor postulado por Husserl que para compreender o mundo é preciso uma experiência, um vínculo com a realidade que nos cerca. Em outros termos, a consciência do mundo é a condição de uma possível consciência de si mesmo. (DEPRAZ, 2008, p. 34)

A originalidade da noção husserliana está justamente na ideia da "subjetividade transcendental". "A epoché fenomenológica liberou uma esfera de ser nova e infinita, como esfera de uma experiência nova, a experiência transcendental". Mas, de imediato, não parece ser tão claro o que haveria de inédito nesta subjetividade chamada de transcendental, face à sua homônima mundana. A responsável pela novidade é a redução, única operação capaz de desvelar o "território fenomenológico". A redução, compreendida como "suspensão da tese geral da atitude natural", ou seja, a redução requer a suspensão das atitudes, crenças, teorias, e coloca em suspenso o conhecimento das coisas do mundo 
exterior a fim de concentrar-se a pessoa exclusivamente na experiência em foco, porque esta é a realidade para ela. (MOURA, 2006, p. 39)

Nesse sentido, Husserl censurava a filosofia de Kant considerando-a "mundana”, isto é, Husserl criticava a utilização do mundo como imanente ao sujeito. Ele achava que a admiração do mundo e a concepção do sujeito transcendental o levaria ao entendimento das coisas. (MERLEAU-PONTY, 1999, prefácio, p. 10)

Husserl teria se preocupado com a elucidação da noção de consciência fenomenológica transcendental, ou seja, daquilo que é objeto da consciência. Nesse sentido, ele preocupa-se em resolver a concepção da atitude natural da consciência. Para ele a consciência transcendental é como um ponto de convergência das atitudes humanas, que permite mostrar o que estamos dizendo ou fazendo o que fazemos como seres humanos. (ARAUJO, 2007, p. 68)

Com a noção de intencionalidade, Husserl procura explicar como a consciência e o vivido se encontram encerrados em si mesmos. A intencionalidade para Husserl é uma relação entre o fenômeno e a vivência. Dessa forma a intencionalidade é constituída através do caráter intencional da consciência, dado no princípio husserliano, já citado anteriormente, de que "toda consciência é consciência de alguma coisa" e que sem essa relação à compreensão do mundo seria impossível. (id, p. 71)

A fenomenologia husserliana será, portanto o estudo dos fenômenos puros ou absolutos, isto é, uma fenomenologia pura. Trata-se de um método derivado de uma atitude, que se presume ser absolutamente sem pressupostos, tendo como objetivo proporcionar ao conhecimento filosófico as bases sólidas de uma ciência de rigor. A fenomenologia implica uma reflexão racional e, portanto, pretende descrever fielmente os fenômenos, considerados como aparecimentos na consciência. (GONÇALVES, 2008, p. 406)

Para Husserl, o aspecto transcendente está nos objetos e naquilo que percebemos deles, e a partir de nossas experiências atribuímos-lhes valores, representações e juízos. O aspecto realista da fenomenologia de Husserl baseia-se na essência da intencionalidade, o qual relaciona o mundo com a consciência, sem fazer da consciência uma parte do mundo. A consciência para Husserl é uma corrente de experiências vividas, tendo cada uma delas a sua essência, aos quais 
os objetos transcendentes se anunciam ou se dá de um modo mais ou menos adequado.

O conhecimento fenomenológico, em Husserl, define que ele se estabelece através dos sentidos, que se apresentam à consciência enquanto consciência que se dirige para os fenômenos. Dessa maneira, a fenomenologia para Husserl deve, pois, para se tornar um puro saber, se afastar de todo tipo de subordinação e vícios, principalmente aqueles constituídos nos sistemas de pensamentos advindos da tradição filosófica. Husserl propõe que o impulso a investigação não deve surgir da filosofia, mas sim dos problemas. Desta feita, entende-se que os fenômenos, dentro da ótica fenomenológica devem se tornar factíveis, devem ser observados e descritos para se apreender as essências dos eventos. (ARAUJO, 2007, p. 70)

A partir do princípio da intencionalidade de Husserl, permitiu-se formular aquilo que se chamou de "redução fenomenológica". A redução fenomenológica nos remete às experiências e ao mundo originais, sem considerar as teorias que lhe foram acrescentadas pelas ciências. (NOGUEIRA, 2004, p. 214)

Assim, as experiências vividas são resultados da interação e do envolvimento do homem com e no mundo, ou dos homens que a vivem. A redução coloca 0 conhecimento vivido de lado, não o despreza, pelo contrário, o compreende no sentido de entender a constituição do mundo a partir daquele que a experiencia. (id, p. 214)

Para Husserl, entender o mundo vivido seria possível quando a individualidade fosse ultrapassada e se chegasse ao caráter plenamente objetivo deste "mundo", o que é conseguido quando se compreende a sua constituição para uma pluralidade de sujeitos - sua constituição intersubjetiva. A intersubjetividade acontece no momento em que o corpo, como elemento móvel, coloca-se em contato com o exterior e localiza o outro, comunicando-se com outros homens e conhecendo outras situações.

É a idéia da intersubjetividade de Husserl que pode nos sugerir linhas mestras no pensamento humanista da Geografia, no sentido de ajudar no diálogo entre a pessoa e o seu espaço, pois ela parte da idéia de "herança sócio-cultural" e do "papel de cada um no mundo vivido". A geografia de Dardel, por exemplo, primava por essa compreensão, ou melhor, de pensar e compreender o lugar a partir das 
coisas que nos parecem óbvias. (BUTTIMER, 1982, p. 168)

Porém, sobre as idéias de Husserl, encontramos muitos fatores que foram temas de vários debates e críticas. Mesmo porque, encontramos em Merleau-Ponty, um grande crítico dos pensamentos husserlianos. Principalmente quando Husserl rompe de vez com o psicologismo dos seus pensamentos a partir da "redução fenomenológica". As críticas de Merleau-Ponty estão relacionadas à posição de Husserl em relação às condições do fato. Nesse caso, o eu filosófico recua em relação às coisas do mundo e procura conhecê-las, percebê-las e compreendê-las, mas sem deixá-las agir à sua revelia. Assim a filosofia tenta explicar com rigidez, como são as manifestações do mundo e das pessoas. Para Merleau Ponty, a Filosofia é muito mais do que isso:

Se de fato refletimos, perceberemos que o sujeito assim situado no mundo e sofrendo sua ação é também aquele que pensa o mundo; é inconcebível um mundo que não fosse pensado por alguém, e, portanto que, se é verdade que o sujeito empírico é uma parte do mundo, é igualmente verdade que o mundo nada mais é que um objeto intencional para o sujeito transcendental. (MERLEAU-PONTY, 1973, p. 31)

Assim para Merleau-Ponty, a grande crítica está na recusa de Husserl em aceitar que da Psicologia se faça Filosofia. Segundo o autor a psicologia realmente considera o homem, mas o homem como uma parte do mundo. Ou seja, a consciência humana é entendida como objeto de estudo e ela é percebida como uma coisa entre as coisas do mundo. (id, 1973, p. 31)

Dessa maneira entendemos que a visão materialista do homem em relação ao seu entendimento do espaço deve ser superada e dar lugar a um novo entendimento, mais voltado às questões existenciais do homem, que estão além das coisas materiais e dos objetos que os cercam, mas que estão no íntimo do ser humano. 


\section{CONCLUSÕES}

A partir desse estudo pode-se analisar a dificuldade das ciências humanas, em particular da Geografia no paradigma humanista-cultural, em abordar temas que requerem entender as relações humanas e suas variáveis. No entanto, se para tal compreensão, utilizarem-se métodos científicos tradicionais e cartesianos, pouco teremos de conhecimento sobre o ser humano e suas relações espaciais.

Os seres humanos não estão nos números das tabelas nem se encaixam em abordagens teoréticas sem sentido para o ser. Desta feita uma outra abordagem que valorize as relações humanas do homem com o espaço vivido faz-se necessária para essa linha de pensamento. Essa abordagem, mais transcendental, e de certa forma mais alinhada com o espírito humano, abre realmente outras possibilidades no pensamento geográfico acerca da compreensão da sociedade atual.

Longe de se autoproclamar como detentora das respostas sobre os valores e sentidos da vida, a fenomenologia existencialista, tem o intuito de encontrar os caminhos para a construção de valores e atitudes e para confrontar novos desafios que se impõem diariamente na humanidade.

\section{REFERÊNCIAS}

ABBAGNANO, Nicola. História da Filosofia. Tradução de Conceição Jardim, Eduardo Lúcio e Nuno Valadas. 4 ed. - Editorial Presença; Lisboa, 2001.

ARAÚJO, Luiza M. G. Ciência, Fenomenologia e Hermenêutica: Diálogos da Geografia para os Saberes Emancipatórios. Tese de Doutoramento da UFMG. Instituto de Geociência da UFMG. Belo Horizonte, 2007.

BERTOL, L. Fenomenologia, Semiótica e Geografia da Percepção: Alternativas para analisar o Espaço Geográfico. Revista da Casa da Geografia de Sobral, Sobral, v. 4/5, p. 67-79, 2002/2003.

BUTTIMER, Anne. Aprendendo o dinamismo do Mundo Vivido. In: CHRISTOFOLETTI, Antônio (Org.). Perspectivas da Geografia. São Paulo: Difel, 1982. (p. 165-194)

DEPRAZ, Natalie. Compreender Husserl. Tradução de Fábio Santos. 2 ed. Petrópolis, RJ: Vozes, 2008. 
GONÇALVES, L.F. Geografia Humanística e Turismo: Contribuições de enfoque Humanista para o Estudo do Turismo. Artigo apresentado no V Seminário de Pesquisa em Turismo do MERCOSUL (SeminTUR). Universidade de Caxias do Sul, RS, Brasil, 27 e 28 de Junho de 2008.

KANT, Imannuel. Crítica da Razão Pura. Tradução de Valério Rohden e Udo Baldur Moosburger. Ed. Nova Cultural Ltda; São Paulo, 2005. (coleção Pensadores)

Crítica da Razão Prática. Tradução de Antônio Carlos Braga. - Editora Escala; São Paulo, 2006.

MERLEAU-PONTY, Maurice. Ciências do homem e fenomenologia. Tradução de Salma Tannus Muchall. - São Paulo: Saraiva, 1973.

1969

O olho e o espirito. Trad. De Gerardo Dantas Barreto. - Grifo Edições,

Fenomenologia da Percepção. 2. ed. São Paulo: Martins Fontes, 1999.

MOURA, Carlos Alberto Ribeiro de. Husserl: significação e fenômeno. Artigo aceito em 31 de janeiro de 2006. Curitiba, São Carlos, vol. 3, n. 1, p.37-61, 2006.

NOGUEIRA, Amélia R. B. Uma Interpretação Fenomenológica na Geografia. In: SILVA, Aldo A.D, Org.; GALENO, Alex, Org. Geografia: Ciência do Complexus: Ensaios Transdisciplinares. Organização de Aldo Aloísio Dantas da Silva e Alex Galeno. Porto Alegre: Sulina, 2004. (p. 209-236)

PASCAL, Georges. Compreender Kant. 5 Ed. - Petrópolis, RJ: Vozes, 2009.

SPOSITO, Eliseu Savério. Geografia e Filosofia: contribuição para o ensino do pensamento geográfico. - São Paulo: Editora UNESP, 2004.

TUAN, Yi-Fu. Espaço e lugar: a perspectiva da experiência. Trad.de Livia de Oliveira. São Paulo: Difel, 1983.

(Recebido em 20.05.2011. Aceito em 16.06.2011) 